\title{
Comparison of mechanical ventilatory constraints between continuous and intermittent exercises in healthy prepubescent children.
}

\begin{tabular}{|c|c|}
\hline Journal: & Pediatric Pulmonology \\
\hline Manuscript ID: & PPUL-09-0314.R3 \\
\hline Wiley - Manuscript type: & Original Article \\
\hline $\begin{array}{r}\text { Date Submitted by the } \\
\text { Author: }\end{array}$ & $16-N o v-2010$ \\
\hline Complete List of Authors: & $\begin{array}{l}\text { Borel, Benoit; Univ Lille Nord de France, F-59000 Lille, UDSL, EA } \\
\text { 3608, Faculté des Sciences du Sport et de I'Education Physique } \\
\text { Leclair, Erwan; Univ Lille Nord de France, F-59000 Lille, UDSL, EA } \\
\text { 3608, Faculté des Sciences du Sport et de I'Education Physique } \\
\text { Thevenet, Delphine; ENS Cachan - Antenne de Bretagne, Campus } \\
\text { de Ker-Lann, Laboratoire Mouvement, Sport, Santé } \\
\text { BEGHIN, Laurent; CHRU de Lille, Centre d'Investigation Clinique } \\
\text { Gottrand, Frédéric; Univ Lille Nord de France, F-59000 Lille, EA } \\
\text { 3925, CHRU de Lille } \\
\text { Fabre, Claudine; Univ Lille Nord de France, F-59000 Lille, UDSL, EA } \\
\text { 3608, Faculté des Sciences du Sport et de I'Education Physique }\end{array}$ \\
\hline Keywords: & children, exercise modality, ventilatory response, flow/volume loop \\
\hline
\end{tabular}




\section{Title Page}

Title: Comparison of mechanical ventilatory constraints between continuous and intermittent exercises in healthy prepubescent children.

Benoit BOREL1-2; Erwan LECLAIR1-2; Delphine THEVENET33; Laurent BEGHIN4-5, Frédéric GOTTRAND ${ }^{5}$ and Claudine FABRE1-2.

1: $\quad$ Univ Lille Nord de France, F-59000 Lille, France.

2: UDSL, EA 4488, Faculté des Sciences du Sport et de l'Education Physique, F59790 Ronchin, France.

3: M2S, ENS Cachan - Antenne de Bretagne, Campus de Ker-Lann, France.

4: Centre d'Investigation Clinique, CIC-9301-CHRU-INSERM de Lille IFR 114 ; Institut de Médicine Prédictive et Thérapeutique de Lille, Lille - France.

5: Interrelations nutrition, inflammation, et infection au cours des maladies respiratoires chroniques de l'enfant (EA 3925), Université de Lille 2 Droit et Santé, Faculté de médecine, Lille - France.

\section{Corresponding author :}

Claudine Fabre, EA 3608,Faculté des Sciences du Sport et de l'Education Physique, 9 rue de l'université 59790 RONCHIN - FRANCE

Tel : +33 (0)320887376/Fax : +33(0)320887363/

Email : benoit.borel-2@univ-lille2.fr /

Running title: Mechanical ventilatory constraints in children 


\section{$1 \quad$ Abstract}

2 Background: The aim of this study was to evaluate the occurrence and severity of mechanical

3 ventilatory constraints in healthy prepubescent children during continuous and intermittent exercise.

$4 \quad$ Methods: Twelve prepubescent children ( $7-11$ years old) performed 7 exercises on a treadmill: one 5 graded test for the determination of maximal aerobic speed (MAS), three continuous exercises (CE) 6 at 60,70 and $80 \%$ of MAS and three intermittent exercises (IE), alternating $15 \mathrm{~s}$ of exercise with $15 \mathrm{~s}$ of 7 passive recovery, at 90, 100 and $110 \%$ of MAS. During each CE and IE, tidal flow/volume loops were 8 plotted within a maximal flow/volume loop (MFVL) measured at rest before each exercise. Expiratory 9 flow limitation (expFL expressed in \% Vt) was defined as the part of exercise tidal volume (Vt) meeting 10 the boundary of MFVL. Breathing strategy was estimated by measuring inspiratory capacity relative 11 to forced vital capacity and tidal volume relative to inspiratory capacity. Other breathing pattern parameters (ventilation VE, Vt, respiratory frequency $f$ ) were continuously recorded during exercise.

Results: An "intensity" effect was found for VE during CE $(p<0.001)$ but not during IE $(p=0.08)$. The 14 increase in $\dot{V} E$ was predominantly assumed by an increase in $f$ for both exercise modalities. During 15 each exercise, several children heterogeneously experienced expFL ranging between $10-90 \% \mathrm{Vt}$. For all exercises, Vt was predominantly regulated by an increase in Vt/IC with no change in IC/FVC from 17 rest to exercise. Finally, no significant "modality" effect was found for mechanical ventilatory 18 constraint parameters (expFL, VT/IC and IV/FVC).

Discussion: We could conclude that neither of the modalities studied induced more mechanical ventilatory constraints than the other, but that exercise intensities specific to each modality might be greater sources of exacerbation for mechanical ventilatory constraints.

Keywords: children, exercise modality, ventilatory response, flow/volume loop 
3 In the literature, it has been reported that children show specific ventilatory adaptations in 4 comparison with adults during exercise. In fact, children present a phenomenon of hyperventilation 5 for a similar level of relative intensity in comparison with adults. This phenomenon of 6 hyperventilation in children is characterized by a higher respiratory equivalent in oxygen $\left(\dot{\mathrm{VE}} / \dot{\mathrm{V}}_{2}\right)$

7 in children than in adults ${ }^{1-4}$ and could result from a specific breathing pattern. The latter is 8 characterized by rapid and shallow breathing in children, defined by higher values of respiratory 9 frequency and lower values of tidal volume than in adults ${ }^{5}$.

\section{Introduction}

Moreover, as already shown in adults during incremental exercise, mechanical ventilatory constraints were also highlighted in children during exercise ${ }^{6-12}$. Such constraints represented the balance between ventilatory demand and ventilatory capacity ${ }^{6}$ and could easily be identified by estimating breathing reserve $(B R)^{6}$. However, BR provides no information on breathing pattern, or on the source and type of ventilatory constraints. This type of information could be obtained by using the exercise flow/volume loops method, consisting in plotting tidal flow/volume loops within maximal flow/volume loops during exercise ${ }^{6}$. By using this method, some studies have assessed mechanical ventilatory constraints in children during incremental exercise and reported several cases of expiratory flow limitation during high intensities of the incremental exercise ${ }^{13,14}$. Thus, Nourry et al reported an "intensity" effect for mechanical ventilatory constraint occurrence and severity during a maximal graded test in trained or untrained prepubescent children ${ }^{13,14}$. From these results, we have hypothesized that intermittent exercise could induce higher mechanical ventilatory constraints than continuous exercise, as the exercise intensities prescribed for intermittent exercises are higher than those prescribed for continuous exercises. The answers to this question could enlighten us on specific ventilatory adaptations in children during two exercise modalities frequently encountered 
1 during everyday life, contrary to current data from the literature, which is only based on incremental 2 exercise.

3

4 The aim of this study was 1 ) to evaluate and compare breathing pattern and tidal flow/volume loops

5 between continuous and intermittent exercises in healthy prepubescent children, so as to determine

6 if both exercise modalities could induce mechanical ventilatory constraints and 2) to determine the

7 effects of the exercise modality on the severity of potential ventilatory constraints, in order to

8 determine if one exercise modality was more restrictive than the other on the children's ventilatory 9 system.

10 


\section{$1 \quad$ Methods}

2

3

4 Twelve $7-11$ year old healthy prepubescent children volunteered to participate in this study, which

5 had previously received approval from the local ethics committee. Parents and children were

6 informed as to the modalities of the study and then gave their written, informed consent prior to any

7 involvement in it. All the children were free of respiratory or cardiac diseases and of orthopedic counter indications for physical exercise, performed less than 3h/week of extra academic physical activity and their sum of pubertal stages was lower than 3 . Sexual maturity was evaluated from pubertal stages, according to Tanner's method: indices of breast, pubic hair and genital development ${ }^{15}$. The same physician made all the observations for all the children.

\section{Study design}

All the children came to the laboratory three times within a one-month period, with at least 48 hours between two evaluation days. At the beginning of each visit, a resting ECG and a clinical examination were performed. During the first visit, spirometry and sexual maturity were evaluated, followed by a period of familiarization and realization of a maximal graded test on a treadmill. Measurement of pulmonary gas exchanges allowed the determination of peak oxygen uptake $\left(\dot{\mathrm{V}}_{2 \text { peak }}\right)$ and maximal aerobic speed (MAS). During the last two visits, the children performed three continuous (continuous visit) and three intermittent (intermittent visit) exercises on the treadmill in a random order. Prior to the exercises, spirometry was performed and, subsequent to them, measurements of pulmonary gas exchanges, heart rate and exercise flow/volume curves were carried out. 
1 At each visit, the children underwent spirometry before each of the exercises performed (Vmax

2 Encore, Sensormedics, Viasys Healthcare, USA). Each child was seated on a chair and fitted with a

3 noseclip. All the lung tests were carried out by the same physician respecting American Thoracic

4 Society recommendations ${ }^{16}$. For each child, three measurements of maximal flow/volume loops

5 (MFVL) were carried out, allowing the determination of forced vital capacity (FVC) and forced

6 expiratory volume in 1 second $\left(\mathrm{FEV}_{1}\right)$. Among the registered measurements, the MFVL with the

7 greatest combination of $\mathrm{FVC}$ and $\mathrm{FEV}_{1}$ was retained.

9 Cardio-respiratory parameters

10 At each visit and during all exercise tests, the children wore a mouthpiece connected to a breath-by-

11 breath gas analyzer (V max Encore laboratory system, Sensormedics, Viasys Healthcare, USA),

12 allowing the measurement of oxygen uptake $\left(\dot{\mathrm{V}}_{2}\right)$, carbon dioxide output $\left(\dot{\mathrm{VCO}}_{2}\right)$, ventilation

$13(\dot{\mathrm{VE}})$, tidal volume $(\mathrm{Vt})$ and respiratory frequency $(f)$. In order to ensure accurate measurements, $\mathrm{O}_{2}$ 14 and $\mathrm{CO}_{2}$ analyzers were calibrated before each exercise test, using ambient air and two gases of

15 known $\mathrm{O}_{2}$ concentration ( $16 \%$ and $26 \%$ ) and $\mathrm{CO}_{2}$ concentration ( $4 \%$ and $0 \%$ ). The calibration of the 16 pneumotachograph was performed using a 3-liter syringe following the manufacturer's 17 recommended procedures.

18 Heart rate (HR) was continuously monitored with a heart rate monitor (Polar S810, Polar Electro Oy, 19 Kempele, Finland). The data acquisition frequency for HR was set at 5 sec.

20 Borg's CR-10 scale ${ }^{17}$ (ranging from 0 to 10 ) was used during all the exercises in order to evaluate 21 dyspnea. This scale was explained to the children at the beginning of each visit and was shown to 22 them at the end of each exercise.

24 Maximal graded test 
1 A period of familiarization on the treadmill was proposed for all the children, consisting in explaining

2 the security procedures and letting them walk and run on it. After explaining the exercise to the

3 children, the test began with a resting period of three minutes in a standing position on the treadmill.

4 Subsequently, a warm-up period of 3 minutes at $3 \mathrm{~km} \cdot \mathrm{h}^{-1}$ was performed. The exercise began with

5 one minute at $4 \mathrm{~km} \cdot \mathrm{h}^{-1}$, then the speed was increased by $0.5 \mathrm{~km} \cdot \mathrm{h}^{-1}$ every minute. During the whole exercise, pulmonary gas exchanges and heart rate were continuously recorded and the values were averaged every 30 seconds. The exercise ended when the children were no longer able to maintain the imposed running speed. It was judged that they had performed a maximal exercise when 3 or more of the following criteria were obtained: visible exhaustion (excessive hyperpnea, facial flushing, sweating, discomfort $)^{18}$, maximal heart rate $>90 \%$ of predicted maximal heart rate $(208-0.7 \times \text { age })^{19}$, a 11 plateau in $\dot{\mathrm{V}}_{2}$ despite increasing running speed or a final respiratory exchange ratio (RER) higher than $1.0^{20}$. The maximal aerobic speed (MAS), corresponding to the speed at the last completed stage ${ }^{21}$, was used as a reference value for the calculation of the individualized speeds of the continuous and intermittent exercises.

\section{Continuous and intermittent visits}

At each of the two other visits, the children performed 3 continuous (CE) or 3 intermittent exercises (IE). Figure 1 shows the design for each exercise-testing visit. First, children rested for three minutes. Then, a 6-minute exercise period was carried out, immediately followed by a 4-minute period of passive recovery, with measurement of gas exchanges. After that, the mouthpiece of the pulmonary gas exchange apparatus was removed until the next exercise. Between two exercises, a 30-minute rest period was observed, without taking any measurements. For the continuous exercises, the 6minute exercise period was performed at an individualized and constant speed. For intermittent exercises, the exercise period was divided into periods of $15 \mathrm{~s}$ of running followed by $15 \mathrm{~s}$ of passive recovery, except for the last minute of each intermittent exercise which was divided into one 30s 
1 period of running and one 30 s period of passive recovery, so as to perform exercise tidal

2 flow/volume loop measurement. In order to avoid the inertia of the treadmill for the two exercise

3 modalities, the treadmill belt was set in motion at the adequate running speed before the beginning

4 of the exercise period. The children were instructed to put their feet on both sides of the belt of the

5 treadmill and to get on the belt at the beginning of the exercise period. For intermittent exercises, as

6 the treadmill was not stopped at the end of each 15-second running period, the children were

7 instructed to get on or off the treadmill after each 15-second period of running or passive recovery.

8 Leaving the treadmill consisted in putting their feet on both sides of it. Hence, the children were

9 familiarized with getting on or off the treadmill before the intermittent exercises and were helped by an adult.

Continuous exercises intensities corresponded to 60\% (CE60), 70\% (CE70) and 80\% (CE80) of MAS. These intensities were always performed in this order. The intermittent exercise intensities corresponded to $90 \%$ (IE90), 100\% (IE100) and 110\% (IE110) of MAS and here also, this order was kept for all the subjects. These MAS intensity percentages were chosen as they are frequently used for continuous and intermittent exercises respectively ${ }^{22}$. Three intensity levels could be described: low (CE60 vs. IE90), middle (CE70 vs. IE100) and high (CE80 vs. IE110).

For all the continuous and intermittent exercises performed by the children, the mean values of $\dot{\mathrm{V}} \mathrm{O}_{2}, \dot{\mathrm{VE}}, \mathrm{Vt}, f, \dot{\mathrm{VE}} / \dot{\mathrm{V} O}{ }_{2}, \dot{\mathrm{VE}} / \dot{\mathrm{V} C O}_{2}$ and $\mathrm{HR}$, reported in the "Results" section, were obtained by averaging raw data during the first 30 seconds of the last minute of each exercise. This period of measurement corresponded to the time of exercise flow/volume loop measurement.

\section{Determination of ventilatory constraints}

For each continuous and intermittent exercise, ventilatory constraints were firstly determined with the calculation of breathing reserve (BR). BR was calculated based on maximal $\dot{V} E$ reached during the exercise and the estimated maximal voluntary ventilation (MVV). It corresponded to how closely 
1 the maximal $\dot{\mathrm{V} E}$ achieved during exercise approached MVV. The BR calculation equation was the 2 following:

3

4 5

$$
\mathrm{BR}(\%)=\left[\left(\mathrm{MVV}-\dot{\mathrm{VE}}_{\max }\right) / \mathrm{MVV}\right] \times 100
$$

where MVV was determined according to the following equation ${ }^{6,23}: \mathrm{MVV}=\mathrm{FEV}_{1} \times 35$ and $\dot{\mathrm{V}} \mathrm{E}_{\max }$ corresponded to the maximal value of $\dot{\mathrm{V} E}$ reached during each continuous or intermittent exercise. The MVV was estimated for each exercise performed, with the $\mathrm{FEV}_{1}$ measured just before the exercise.

In order to evaluate mechanical ventilatory constraints and breathing strategy during the exercise, exercise tidal flow/volume loops (tidal F/V loops) were recorded just once, at the end of the first 30 seconds of the last minute of each exercise using a pneumotachograph. Tidal F/V loops corresponded to a mean of ten tidal breaths recorded and were computer averaged before a maximal inspiratory capacity (IC) maneuver. This maneuver allows correction of drift phenomena, as described by Johnson et al ${ }^{6}$. During exercise, a drift phenomenon could appear in the volume signal due to electrical or physiological changes over time. This drift must be corrected in order to obtain correctly placed tidal F/V loops within MFVL. Thus, the maximal inspiratory capacity maneuver was performed immediately after tidal F/V loop measurement. This maximal IC maneuver was compared to the maximal IC determined at rest. After the maneuver, the computer could correctly plot tidal F/V loops within the MFVL determined before the exercise. For each tidal F/V loop measurement, the mean values of $\dot{\mathrm{V}} \mathrm{O}_{2}, \dot{\mathrm{VE}}, \mathrm{Vt}, f, \dot{\mathrm{VE}} / \dot{\mathrm{V}}_{2}, \dot{\mathrm{VE}} / \dot{\mathrm{VCO}}_{2}$ and $\mathrm{HR}$ were calculated at the moment of measurement (corresponding to the mean of the first 30 seconds of the last minute of exercise).

Expiratory flow limitation (expFL) corresponds to the part of tidal F/V loop that meets or exceeds the expiratory boundary of the MFVL and is expressed as a \% of tidal volume (\%Vt). In order to determine breathing strategy, the evolution of different ratios was analyzed. Hence, inspiratory 
1 capacity (IC) relative to forced vital capacity $(\mathrm{IC} / \mathrm{FVC})^{6}$, expiratory reserve volume relative to vital

2 capacity (ERV/FVC), tidal volume relative to inspiratory capacity $(\mathrm{Vt} / \mathrm{IC})^{6}$ and inspiratory reserve

3 volume relative to vital capacity (IRV/FVC) were computed (Figure 2).

4

5 Statistical analysis

6 All the values were expressed as means \pm standard deviation (mean \pm SD). For each parameter, data

7 normality was verified with a Kolmogorov-Smirnov test.

8 In order to determine the effect of exercise modality, a two-way repeated measure analysis of 9 variance (ANOVA) was performed for all the parameters. The factors were "exercise intensity" and 10 "exercise modality". When the ANOVA F ratio was significant, the mean values were compared by 11 using pairwise multiple comparison procedures (Bonferroni post-hoc test).

12 For intra-modality comparison, a one-way repeated measure analysis of variance (ANOVA) was 13 performed for all the parameters. The factor was "exercise intensity". When the ANOVA F ratio was 14 significant, the mean values were compared by using pairwise multiple comparison procedures 15 (Bonferroni post-hoc test).

16 For rest versus exercise values comparison within the same modality, a "paired t-test" was carried 17 out.

18 For all the tests, significance was set at the 0.05 level. 


\section{Results}

2

3 Anthropometric, spirometric and maximal values at incremental exercise

4 Respiratory data from one subject were unworkable. Thus, anthropometric, spirometric and maximal 5 exercise values of the eleven children were analyzed ( 8 boys and 3 girls; Table 1). For each child, 3

6 criteria of maximality at least were fulfilled, showing that the graded exercise was maximal.

7

8 Mean cardiorespiratory values $\left(\dot{\mathrm{VO}}_{2}, \mathrm{HR}, \mathrm{RER}\right)$ measured during continuous and intermittent

exercises for the whole population are shown in Table 2. For $\dot{\mathrm{V}} \mathrm{O}_{2}$ only, a significant "intensity $\mathrm{x}$ modality" interaction and an "intensity" effect were highlighted. However post-hoc tests revealed no significant difference between continuous and intermittent exercises within the three different intensity levels (ie. CE60 vs. IE90, CE70 vs. IE100 and CE80 vs. IE110), allowing the comparison of the ventilatory data obtained during each exercise modality. For $\mathrm{HR}$, an significant intensity effect was highlighted for both modalities, without "modality" effect. Finally, no effect of the exercise modality and intensity was found for Respiratory Exchange Ratio (RER).

\section{Ventilatory response to exercise}

\section{Breathing pattern}

The mean values of ventilation are shown in Table 3. Two-way ANOVA analysis highlights "intensity" and "modality $x$ intensity" interaction effects for ventilation $(p<0.05)$. An "intensity" effect $(p<0.001)$ was found for $\dot{\mathrm{VE}}$ in continuous exercise $(p<0.001)$ but not in intermittent exercise $(p=0.08)$. Following post-hoc tests, for each level of exercise intensity (CE60 vs. IE90, CE70 vs. I100 and CE80 vs. IE110), ventilation and dyspnea scores were not significantly different between continuous and intermittent exercises. For tidal volume (Vt), no "intensity" or "modality" effects were found for 
1 either CE or IE modalities. Concerning respiratory frequency $(f)$, an "intensity" effect was found for IE

$2 \quad(p<0.05)$ and a tendency towards significant effect for CE $(p=0.06)$. No "modality" effect was found

3 for this parameter.

4

5

6

7

8

9

10

11

12

13

14

Mechanical ventilatory constraints

- Expiratory flow limitation

Expiratory flow limitation (expFL) was experienced by 1 child during CE60, 6 children during CE70 and

6 children during CE80. Concerning intermittent exercise, expFL was observed for 3,4 and 6 children during IE90, IE100 and IE110 respectively (Figure 3.b). Individual values of ExpFL ranged between 10 $-90 \%$ of Vt. Only one child showed expFL during all the continuous and intermittent exercises. Mean values of expFL for the whole population ranged from $5 \%$ to $29 \%$ of $\mathrm{Vt}$ and from $13 \%$ to $23 \%$ of $\mathrm{Vt}$ for the continuous and intermittent exercises respectively (Figure 3.a).

- Flow-limited (FL) vs. non flow-limited (NFL) comparison

Within each exercise, the population was divided into two groups according to the presence or absence of an expiratory flow limitation (expFL) during exercise. The children who presented expFL made up the flow-limited group (FL group). The non flow-limited group (NFL) was composed of the other children.

For continuous exercise at $60 \%$ of MAS, only one child experienced an expFL versus 10 children making up the NFL group, which made comparison impossible.

No significant difference was highlighted between the two groups for breathing pattern ( $\mathrm{Vt}$ and $f$ ) in any of the exercises.

Breathing reserve was significantly lower in the FL than the NFL group during continuous exercise, for CE70 (30.8 \pm 11.6 for FL and $48.8 \pm 10.2$ for NFL; $p=0.02)$ and CE80 $(21.8 \pm 10.1$ for FL and $42.1 \pm 10.9$ for NFL; $p=0.01$ ). During all intermittent exercises, no significant difference for BR was found 


\section{1}

2

1 between FL and NFL groups for IE90 (38.8 \pm 1.2 for FL and $50.9 \pm 10.2$ for NFL), IE100 (33.9 \pm 7.9 for

2 FL and $45.2 \pm 12.2$ for NFL) and IE110 ( $24.2 \pm 22.2$ for FL and $46.7 \pm 13.9$ for NFL).

3

$4 \quad$ - Flow volume loops and tidal volume regulation.

5 The mean values of resting and exercise pulmonary parameters are recapitulated in Table 4. IRV

6 decreased significantly from rest to exercise for all continuous or intermittent exercises $(p<0.05)$. ERV

7 increased significantly from rest to exercise for CE70, IE100 and IE110 ( $p<0.05)$. For IC, a significant

8 difference was observed between rest and exercise for CE70, IE100 and IE110 ( $p<0.05)$. No significant

9 differences were found for IC/FVC and ERV/FVC between rest and exercise values, except for IE110

10 ( $p<0.05)$. IRV/FVC decreased significantly between rest and exercise for all the exercises. In the same 11 way, Vt/IC was significantly higher than at rest for all the exercises except for CE70 and IE100 $12(\mathrm{p}<0.05)$.

14 For all the parameters of mechanical ventilatory constraints (expFL, Vt/IC, IC/FVC, IRV/FVC and 15 ERV/FVC), there were no significant "modality" and "intensity" effects (Table 4 and Figure 3.a). 16 However, an "intensity" effect tended to be significant for expFL during continuous exercise $17 \quad(p=0.065)$ 


\section{Discussion}

2 The purpose of the study was to evaluate the ventilatory response during continuous and

3 intermittent exercises and to determine if one of these two exercise modalities could induce greater

4 mechanical ventilatory constraints than the other. Our results showed that both exercise modalities

5 (continuous and intermittent) could induce mechanical ventilatory constraints in healthy

6 prepubescent children, as several children presented expiratory flow limitation (expFL) during

7 continuous and intermittent exercises with no influence due to exercise modality.

8

9 Some limits should be considered for this study, mainly concerning recorded exercise flow/volume 10 loops. As mentioned by some authors ${ }^{6,13}$, expFL assessment is highly dependent on the placement of 11 exercise flow/volume loop within maximal flow/volume loop. This limit has been taken in account 12

As described above, the aim of the study was to compare mechanical ventilatory constraints (expiratory flow limitation and dynamic hyperinflation) and breathing pattern (ventilation, tidal volume and breathing frequency) during continuous and intermittent exercises with exercise intensities inducing similar metabolic demand. Even if a significant interaction for oxygen uptake was highlighted, it appears that, within the different levels of exercise intensity (low, medium and high), the metabolic demand $\left(\dot{\mathrm{V}}_{2}\right)$ was matching for the pair of tasks concerning the two exercise modalities. In other words, no significant difference was highlighted for $\dot{\mathrm{V}} \mathrm{O}_{2}$ between CE60 vs. IE90, CE70 vs. IE100 and CE80 vs. IE110, allowing the comparison of the breathing pattern data and mechanical ventilatory constraints data obtained during each exercise. 
2 As expected, ventilation for the continuous exercise modality increased with greater exercise

3 intensity. However, during intermittent exercises, ventilation increased slightly, but not significantly,

4 with the increase in exercise intensity. These specific ventilation evolutions according to exercise

5 modality could be due to the fact that, during $15 \mathrm{~s}-15 \mathrm{~s}$ intermittent exercises performed by the children in this study, the time of running was rather short. Hence, the ventilatory system would not seem to have enough time to adapt to the ventilatory demand induced by the exercise intensity. However, within the three intensity levels (i.e. low, medium or high), no significant difference was highlighted between continuous and intermittent exercises. These results could logically be explained since the intensities of intermittent exercises were specifically chosen in order to be 11 matched with continuous exercise intensities in terms of energy expenditure (i.e. oxygen uptake), as 12 already reported by Berthoin et al. ${ }^{24}$ The absence of significant difference for ventilation between 13 both exercise modalities was also required in order to compare breathing pattern components (Vt 14 and f) correctly. In fact, several studies have reported that for a particular subject, the regulation of 15 the breathing pattern at a given level of ventilation is largely independent of the cause of the 16 increased ventilation ${ }^{25,26}$.

17 During all the continuous and the intermittent exercises, our results showed that the increase in 18 ventilation was mainly due to an increase in respiratory frequency. This result supports the findings 19 in the literature ${ }^{5}$ and revealed that, whatever the exercise modality, children presented rapid and 20 shallow breathing. However, differences in ventilatory regulation according to exercise modality 21 seemed to exist, as a "modality" effect was found for ventilatory equivalent in carbon dioxide $22\left(\dot{\mathrm{VE}} / \dot{\mathrm{VCO}}_{2}\right)$. Post-hoc analysis revealed that, in general, intermittent exercise modality induced higher $\dot{\mathrm{V} E} / \dot{\mathrm{VCO}}_{2}$ values than continuous exercise modality. This could be explained firstly, by a 24 chemical regulation due to a higher acidosis level during intermittent exercise and, secondly, by a 
1 movement frequency encountered during intermittent exercise which could induce a greater

2 ventilatory response ${ }^{27}$.

3

4

5 As described by Johnson et al ${ }^{6}$, the assessment of breathing reserve (BR) could be an indicator of the

\section{Effects of exercise intensity on mechanical ventilatory constraints} occurrence of mechanical ventilatory constraints during exercise. In all the previous studies reporting BR values in children, the exercise performed has been incremental ${ }^{13,14,28-30}$. This difference in protocols makes it impossible to compare our results with the previous studies, which is normal, since this is the originality of our study. In our study, BR significantly decreased during CE and IE whereas there was no "intensity" effect for VE during IE. This result is surprising and reinforces the work of Johnson et al. ${ }^{6}$ asserting that breathing reserve is a general and inappropriate parameter for the study of mechanical ventilatory constraints during exercise.

The study of mechanical ventilatory constraints with exercise flow/volume loops brings more information on the adaptation of the ventilatory system during exercise.

In our study, the number of expiratory flow limitation cases increased with exercise intensity in both exercise modalities. For the highest intensity exercises, more than $50 \%$ of the whole population ( 6 of the 11 children studied) showed an expiratory flow limitation. Individual expiratory flow limitation ranged between $10-90 \%$ of $\mathrm{Vt}$. These values are in accordance with values of expFL found in the literature. In fact, Nourry et al. ${ }^{13}$ reported an increase in the number of observations of expFL in nonathlete prepubescent children ( 8 children out of the 18 studied) with the increase in intensity during the maximal graded test, ranging between $16-78 \%$ of $\mathrm{Vt}$. The occurrence of expFL during submaximal (CE60, CE70, CE80 and IE90) and supra-maximal (IE100, IE110) exercises is not surprising, since a previous study has reported the case of expFL from $30 \%$ of maximal aerobic power ${ }^{13}$ and intensities prescribed in our study were all higher than this threshold value. As with ventilatory response during exercise, the occurrence of expFL in our population was heterogeneous as some 
1 children experienced expFL during IE90 and IE110 but not during IE100 for example. The

2 heterogeneity of expFL occurrence has also previously been described in children ${ }^{13}$ and could be 3 explained by the different levels of ventilatory system maturation.

4 Thus, for both exercise modalities, the increase in ventilation was generally associated with a 5 significant decrease in IRV and IRV/FVC and an increase in Vt/IC from rest to exercise without significant modification of ERV/FVC and IC/FVC ratios, whatever the exercise performed. These results attested to the absence of dynamic hyperinflation. The absence of significant modification of ERV/FVC and IC/FVC ratios during exercise attested to a specific breathing pattern for children, whatever the exercise modality, in comparison with an adult population.

\section{Effects of exercise modality on mechanical ventilatory constraints}

The exercise modality had no effect on breathing reserve, as similar values were found during continuous and intermittent exercises for the three intensity levels. Tidal volume regulation was not influenced by a "modality" effect either. Following statistical analysis, exercise modality was noted to have no effect on the occurrence and/or the severity of expFL. This absence of "modality" effect invalidated our hypothesis. In fact, as higher intensities are frequently used during intermittent exercises, we had hypothesized that the higher ventilatory demand induced by the high-intensity intermittent exercises would induce greater mechanical ventilatory constraints. The absence of a "modality" effect for ventilation could be an explanation for the absence of a "modality" effect on mechanical ventilatory constraints.

In the present study, the assessment of the ventilatory response corresponded to an intermittent exercise design comprising $15 \mathrm{~s}$ of exercise followed by $15 \mathrm{~s}$ of passive recovery. However many modalities of intermittent exercises exist, such as $30 \mathrm{~s}-30$ s, with passive or active recovery ${ }^{24}$. Our results may only be relevant for this intermittent exercise design. In fact, any change in parameters 
1 defining intermittent exercises could modify the ventilatory response values and so alter the

2 breathing pattern, breathing strategy and the occurrence of mechanical ventilatory constraints

3 during intermittent exercises. Yet, on the other hand, the $15 s-15 s$ design was chosen as this

$4 \quad$ intermittent exercise design has previously been used quite often in the literature and has generally

5 been well accepted by children ${ }^{24,31}$.

6

7 In conclusion, exercise modality does not seem to be a predominant factor in mechanical ventilatory

8 constraint occurrence during exercise. Nevertheless, the exercise intensity seems to be an important

9 factor in inducing mechanical ventilatory constraints, as the number of occurrences and the severity

10 increased with intensity increased. We could conclude that neither of the modalities studied induced

11 more or greater mechanical ventilatory constraints than the other, but exercise intensities specific to

12 each modality might be greater sources of exacerbation for mechanical ventilatory constraints.

13

14

15

16

17

18

19

20

\section{Acknowledgements}

We thank all the children and their parents who took part in this study for their participation and their devotion. Data quality assurance was assumed by Clinical Investigation Center of Lille (CIC-9301Inserm-CHRU). Regulatory aspects were performed by the designed "Good Clinical Practices sponsor" as University Regional Centre Hospital (CHRU). Financial support was assumed by a grant from the French Ministry of Health (regional PHRC n $1904-2005)$. 


\section{References}

1. Nagano $Y$, Baba R, Kuraishi K, Yasuda T, Ikoma M, Nishibata K, Yokota M, Nagashima M. Ventilatory control during exercise in normal children. Pediatr Res 1998;43(5):704-707.

2. Rowland TW, Cunningham LN. Development of ventilatory responses to exercise in normal white children. A longitudinal study. Chest 1997;111(2):327-332.

3. Cooper DM, Kaplan MR, Baumgarten L, Weiler-Ravell D, Whipp BJ, Wasserman K. Coupling of ventilation and CO2 production during exercise in children. Pediatr Res 1987;21(6):568-572.

4. Andersen KL, Seliger V, Rutenfranz J, Messel S. Physical performance capacity of children in Norway. III. Respiratory responses to graded exercise loadings--population parameters in a rural community. Eur J Appl Physiol Occup Physiol 1974;33(4):265-274.

5. Gratas-Delamarche A, Mercier J, Ramonatxo M, Dassonville J, Prefaut C. Ventilatory response of prepubertal boys and adults to carbon dioxide at rest and during exercise. Eur J Appl Physiol Occup Physiol 1993;66(1):25-30.

6. Johnson BD, Weisman IM, Zeballos RJ, Beck KC. Emerging concepts in the evaluation of ventilatory limitation during exercise: the exercise tidal flow-volume loop. Chest 1999;116(2):488-503.

7. Babb TG. Mechanical ventilatory constraints in aging, lung disease, and obesity: perspectives and brief review. Med Sci Sports Exerc 1999;31(1 Suppl):S12-22.

8. DeLorey DS, Babb TG. Progressive mechanical ventilatory constraints with aging. Am J Respir Crit Care Med 1999;160(1):169-177.

9. Babb TG, Viggiano R, Hurley B, Staats B, Rodarte JR. Effect of mild-to-moderate airflow limitation on exercise capacity. J Appl Physiol 1991;70(1):223-230.

10. Johnson BD, Saupe KW, Dempsey JA. Mechanical constraints on exercise hyperpnea in endurance athletes. J Appl Physiol 1992;73(3):874-886.

11. Johnson BD, Reddan WG, Seow KC, Dempsey JA. Mechanical constraints on exercise hyperpnea in a fit aging population. Am Rev Respir Dis 1991b;143(5 Pt 1):968-977.

12. Johnson BD, Reddan WG, Pegelow DF, Seow KC, Dempsey JA. Flow limitation and regulation of functional residual capacity during exercise in a physically active aging population. Am Rev Respir Dis 1991a;143(5 Pt 1):960-967.

13. Nourry C, Deruelle F, Fabre C, Baquet G, Bart F, Grosbois JM, Berthoin S, Mucci P. Evidence of ventilatory constraints in healthy exercising prepubescent children. Pediatr Pulmonol 2006;41(2):133-140.

14. Nourry C, Deruelle F, Fabre C, Baquet G, Bart F, Grosbois JM, Berthoin S, Mucci P. Exercise flow-volume loops in prepubescent aerobically trained children. J Appl Physiol 2005;99(5):1912-1921.

15. Tanner. Growth at Adolescence (2nd Ed.). Oxford, UK; 1962.

16. Society AT. Standardization of spirometry--1987 update. Official statement of American Thoracic Society. Respir Care 1987;32(11):1039-1060.

17. Borg GA. Psychophysical bases of perceived exertion. Med Sci Sports Exerc 1982;14(5):377381.

18. Fawkner SG, Armstrong N, Potter CR, Welsman JR. Oxygen uptake kinetics in children and adults after the onset of moderate-intensity exercise. J Sports Sci 2002;20(4):319-326.

19. Tanaka H, Monahan KD, Seals DR. Age-predicted maximal heart rate revisited. J Am Coll Cardiol 2001;37(1):153-156.

20. Tolfrey K, Campbell IG, Batterham AM. Exercise training induced alterations in prepubertal children's lipid-lipoprotein profile. Med Sci Sports Exerc 1998;30(12):1684-1692.

21. Billat LV, Koralsztein JP. Significance of the velocity at VO2max and time to exhaustion at this velocity. Sports Med 1996;22(2):90-108. 
22. Baquet $\mathrm{G}$, van Praagh $\mathrm{E}$, Berthoin $\mathrm{S}$. Endurance training and aerobic fitness in young people. Sports Med 2003;33(15):1127-1143.

23. Stein R, Selvadurai H, Coates A, Wilkes DL, Schneiderman-Walker J, Corey M. Determination of maximal voluntary ventilation in children with cystic fibrosis. Pediatr Pulmonol 2003;35(6):467-471.

24. Berthoin S, Baquet G, Dupont G, Van Praagh E. Critical velocity during continuous and intermittent exercises in children. Eur J Appl Physiol 2006;98(2):132-138.

25. Hey EN, Lloyd BB, Cunningham DJ, Jukes MG, Bolton DP. Effects of various respiratory stimuli on the depth and frequency of breathing in man. Respir Physiol 1966;1(2):193-205.

26. Gallagher $\mathrm{CG}$, Brown $\mathrm{E}$, Younes $\mathrm{M}$. Breathing pattern during maximal exercise and during submaximal exercise with hypercapnia. J Appl Physiol 1987;63(1):238-244.

27. Takano N. Effects of pedal rate on respiratory responses to incremental bicycle work. J Physiol 1988;396:389-397.

28. Armstrong N, Kirby BJ, McManus AM, Welsman JR. Prepubescents' ventilatory responses to exercise with reference to sex and body size. Chest 1997;112(6):1554-1560.

29. Prioux J, Matecki S, Amsallem F, Denjean A, Ramonatxo M. [Ventilatory response to maximal exercise in healthy children]. Rev Mal Respir 2003;20(6 Pt 1):904-911.

30. Prioux J, Matecki S, Mercier J, Prefaut C, Ramonatxo M. Ventilatory reserve at maximal exercise in children. A transversal study. Pflügers Arch 2000;440:215.

31. Dupont G, Blondel N, Lensel G, Berthoin S. Critical velocity and time spent at a high level of VO2 for short intermittent runs at supramaximal velocities. Can J Appl Physiol 2002;27(2):103-115. 
Figure 3: Expiratory flow limitation during the six performed exercises.

Values are expressed as mean \pm SD. Graph 3.a : mean expiratory flow limitation for the whole population. Graph 3.b : mean expiratory flow limitation for the flow-limited group. ExpFL corresponds to expiratory flow limitation expressed in percentage of tidal volume that meets or exceeds maximal flow/volume loop. Thus, the flow limit group was composed of the children who showed an expFL during exercise.

CE60, CE70 and CE80 correspond to continuous exercise at $60 \%, 70 \%$ and $80 \%$ of maximal aerobic speed; IE90, IE100 and IE110 to intermittent exercise at $90 \%, 100 \%$ and $110 \%$ of maximal aerobic speed. 


\section{Title Page}

Title: Comparison of mechanical ventilatory constraints between continuous and intermittent exercises in healthy prepubescent children.

Benoit BOREL1-2; Erwan LECLAIR ${ }^{1-2}$; Delphine THEVENET33 Laurent BEGHIN ${ }^{4-5}$, Frédéric GOTTRAND ${ }^{5}$ and Claudine FABRE ${ }^{1-2}$.

1: $\quad$ Univ Lille Nord de France, F-59000 Lille, France.

2: UDSL, EA 4488, Faculté des Sciences du Sport et de l'Education Physique, F59790 Ronchin, France.

3: $\quad$ M2S, ENS Cachan - Antenne de Bretagne, Campus de Ker-Lann, France.

4: Centre d'Investigation Clinique, CIC-9301-CHRU-INSERM de Lille IFR 114 ; Institut de Médicine Prédictive et Thérapeutique de Lille, Lille - France.

5: Interrelations nutrition, inflammation, et infection au cours des maladies respiratoires chroniques de l'enfant (EA 3925), Université de Lille 2 Droit et Santé, Faculté de médecine, Lille - France.

Corresponding author:

Claudine Fabre, EA 3608,Faculté des Sciences du Sport et de l'Education Physique, 9 rue de l'université 59790 RONCHIN - FRANCE

Tel : +33 (0)320887376/ Fax : +33 (0)320887363/

Email : benoit.borel-2@univ-lille2.fr /

Running title: Mechanical ventilatory constraints in children 


\section{$1 \quad$ Abstract}

2 Background: The aim of this study was to evaluate the occurrence and severity of mechanical

3 ventilatory constraints in healthy prepubescent children during continuous and intermittent exercise.

$4 \quad$ Methods: Twelve prepubescent children ( $7-11$ years old) performed 7 exercises on a treadmill: one 5 graded test for the determination of maximal aerobic speed (MAS), three continuous exercises (CE) 6 at 60,70 and $80 \%$ of MAS and three intermittent exercises (IE), alternating $15 \mathrm{~s}$ of exercise with $15 \mathrm{~s}$ of 7 passive recovery, at 90, 100 and $110 \%$ of MAS. During each CE and IE, tidal flow/volume loops were 8 plotted within a maximal flow/volume loop (MFVL) measured at rest before each exercise. Expiratory

9 flow limitation (expFL expressed in \%Vt) was defined as the part of exercise tidal volume (Vt) meeting 10 the boundary of MFVL. Breathing strategy was estimated by measuring inspiratory capacity relative 11 to forced vital capacity and tidal volume relative to inspiratory capacity. Other breathing pattern parameters (ventilation VE, Vt, respiratory frequency $f$ ) were continuously recorded during exercise.

Results: An "intensity" effect was found for VE during CE $(p<0.001)$ but not during IE $(p=0.08)$. The increase in $\dot{\mathrm{V} E}$ was predominantly assumed by an increase in $f$ for both exercise modalities. During all exercises, Vt was predominantly regulated by an increase in Vt/IC with no change in IC/FVC from rest to exercise. Finally, no significant "modality" effect was found for mechanical ventilatory constraint parameters (expFL, VT/IC and IV/FVC).

Discussion: We could conclude that neither of the modalities studied induced more mechanical ventilatory constraints than the other, but that exercise intensities specific to each modality might be greater sources of exacerbation for mechanical ventilatory constraints.

Keywords: children, exercise modality, ventilatory response, flow/volume loop 
1

2

3 In the literature, it has been reported that children show specific ventilatory adaptations in

4 comparison with adults during exercise. In fact, children present a phenomenon of hyperventilation

5 for a similar level of relative intensity in comparison with adults. This phenomenon of

6 hyperventilation in children is characterized by a higher respiratory equivalent in oxygen $\left(\dot{\mathrm{VE}} / \dot{\mathrm{V}}_{2}\right)$

7 in children than in adults ${ }^{1-4}$ and could result from a specific breathing pattern. The latter is

8 characterized by rapid and shallow breathing in children, defined by higher values of respiratory

9 frequency and lower values of tidal volume than in adults ${ }^{5}$.

10

Moreover, as already shown in adults during incremental exercise, mechanical ventilatory constraints were also highlighted in children during exercise ${ }^{6-12}$. Such constraints represented the balance between ventilatory demand and ventilatory capacity ${ }^{6}$ and could easily be identified by estimating breathing reserve $(B R)^{6}$. However, BR provides no information on breathing pattern, or on the source and type of ventilatory constraints. This type of information could be obtained by using the exercise flow/volume loops method, consisting in plotting tidal flow/volume loops within maximal flow/volume loops during exercise ${ }^{6}$. By using this method, some studies have assessed mechanical ventilatory constraints in children during incremental exercise and reported several cases of expiratory flow limitation during high intensities of the incremental exercise ${ }^{13,14}$. Thus, Nourry et al reported an "intensity" effect for mechanical ventilatory constraint occurrence and severity during a maximal graded test in trained or untrained prepubescent children ${ }^{13,14}$. From these results, we have hypothesized that intermittent exercise could induce higher mechanical ventilatory constraints than continuous exercise, as the exercise intensities prescribed for intermittent exercises are higher than those prescribed for continuous exercises. The answers to this question could enlighten us on specific ventilatory adaptations in children during two exercise modalities frequently encountered 
1

2 3 4 5

4 The aim of this study was 1 ) to evaluate and compare breathing pattern and tidal flow/volume loops 5 between continuous and intermittent exercises in healthy prepubescent children, so as to determine 6 if both exercise modalities could induce mechanical ventilatory constraints and 2) to determine the 7 effects of the exercise modality on the severity of potential ventilatory constraints, in order to 8 determine if one exercise modality was more restrictive than the other on the children's ventilatory 9 system. 


\section{$1 \quad$ Methods}

2

3

4 Twelve 7-11 year old healthy prepubescent children volunteered to participate in this study, which

5 had previously received approval from the local ethics committee. Parents and children were

6 informed as to the modalities of the study and then gave their written, informed consent prior to any

7 involvement in it. All the children were free of respiratory or cardiac diseases and of orthopedic

8

9 counter indications for physical exercise, performed less than 3h/week of extra academic physical activity and their sum of pubertal stages was lower than 3 . Sexual maturity was evaluated from pubertal stages, according to Tanner's method: indices of breast, pubic hair and genital development ${ }^{15}$. The same physician made all the observations for all the children.

\section{Study design}

All the children came to the laboratory three times within a one-month period, with at least 48 hours between two evaluation days. At the beginning of each visit, a resting ECG and a clinical examination were performed. During the first visit, spirometry and sexual maturity were evaluated, followed by a period of familiarization and realization of a maximal graded test on a treadmill. Measurement of pulmonary gas exchanges allowed the determination of peak oxygen uptake $\left(\dot{\mathrm{VO}}_{2}\right.$ peak $)$ and maximal aerobic speed (MAS). During the last two visits, the children performed three continuous (continuous visit) and three intermittent (intermittent visit) exercises on the treadmill in a random order. Prior to the exercises, spirometry was performed and, subsequent to them, measurements of pulmonary gas exchanges, heart rate and exercise flow/volume curves was were carried out.

\section{Spirometry}


1 At each visit, the children underwent spirometry before each of the exercises performed (Vmax

2 Encore, Sensormedics, Viasys Healthcare, USA). Each child was seated on a chair and fitted with a

3 noseclip. All the lung tests were carried out by the same physician respecting American Thoracic

4 Society recommendations ${ }^{16}$. For each child, three measurements of maximal flow/volume loops

5 (MFVL) were carried out, allowing the determination of forced vital capacity (FVC) and forced expiratory volume in 1 second $\left(\mathrm{FEV}_{1}\right)$. Among the registered measurements, the MFVL with the greatest combination of FVC and $\mathrm{FEV}_{1}$ was retained.

\section{Cardio-respiratory parameters}

At each visit and during all exercise tests, the children wore a mouthpiece connected to a breath-by11 breath gas analyzer (V max Encore laboratory system, Sensormedics, Viasys Healthcare, USA), 12 allowing the measurement of oxygen uptake $\left(\dot{\mathrm{V}} \mathrm{O}_{2}\right)$, carbon dioxide output $\left(\dot{\mathrm{VCO}}_{2}\right)$, ventilation $13(\dot{\mathrm{VE}})$, tidal volume $(\mathrm{Vt})$ and respiratory frequency $(f)$. In order to ensure accurate measurements, $\mathrm{O}_{2}$ 14 and $\mathrm{CO}_{2}$ analyzers were calibrated before each exercise test, using ambient air and two gases of 15 known $\mathrm{O}_{2}$ concentration ( $16 \%$ and $26 \%$ ) and $\mathrm{CO}_{2}$ concentration ( $4 \%$ and $0 \%$ ). The calibration of the 16 pneumotachograph was performed using a 3-liter syringe following the manufacturer's 17 recommended procedures.

18 Heart rate (HR) was continuously monitored with a heart rate monitor (Polar S810, Polar Electro Oy, 19 Kempele, Finland). The data acquisition frequency for HR was set at $5 \mathrm{sec}$.

20 Borg's CR-10 scale ${ }^{17}$ (ranging from 0 to 10 ) was used during all the exercises in order to evaluate 21 dyspnea. This scale was explained to the children at the beginning of each visit and was shown to 22 them at the end of each exercise.

\section{Maximal graded test}


1 A period of familiarization on the treadmill was proposed for all the children, consisting in explaining

2 the security procedures and letting them walk and run on it. After explaining the exercise to the

3 children, the test began with a resting period of three minutes in a standing position on the treadmill.

4 Subsequently, a warm-up period of 3 minutes at $3 \mathrm{~km} \cdot \mathrm{h}^{-1}$ was performed. The exercise began with

5 one minute at $4 \mathrm{~km} \cdot \mathrm{h}^{-1}$, then the speed was increased by $0.5 \mathrm{~km} \cdot \mathrm{h}^{-1}$ every minute. During the whole

6 exercise, pulmonary gas exchanges and heart rate were continuously recorded and the values were

7 averaged every 30 seconds. The exercise ended when the children were no longer able to maintain

8 the imposed running speed. It was judged that they had performed a maximal exercise when 3 or

9 more of the following criteria were obtained: visible exhaustion (excessive hyperpnea, facial flushing, 10 sweating, discomfort $)^{18}$, maximal heart rate $>90 \%$ of predicted maximal heart rate $(208-0.7 \times \text { age })^{19}$, a 11 plateau in $\dot{\mathrm{V}}_{2}$ despite increasing running speed or a final respiratory exchange ratio (RER) higher 12 than $1.0^{20}$. The maximal aerobic speed (MAS), corresponding to the speed at the last completed 13 stage ${ }^{21}$, was used as a reference value for the calculation of the individualized speeds of the 14 continuous and intermittent exercises.

\section{Continuous and intermittent visits}

17 At each of the two other visits, the children performed 3 continuous (CE) or 3 intermittent exercises 18 (IE). Figure 1 shows the design for each exercise-testing visit. A resting period of three minutes was 19 firstly observed First, children rested for three minutes. Then, a 6-minute exercise period was carried 20 out, immediately followed by a 4-minute period of passive recovery, with measurement of gas 21 exchanges. After that, the mouthpiece of the pulmonary gas exchange apparatus was removed until 22 the next exercise. Between two exercises, a 30-minute rest period was observed, without taking any 23 measurements. For the continuous exercises, the 6-minute exercise period was performed at an individualized and constant speed. For intermittent exercises, the exercise period was divided into periods of $15 \mathrm{~s}$ of running followed by $15 \mathrm{~s}$ of passive recovery, except for the last minute of each 
1 intermittent exercise which was divided into one 30 s period of running and one 30 s period of passive

2 recovery, so as to perform exercise tidal flow/volume loop measurement. In order to avoid the

3 inertia of the treadmill for the two exercise modalities, the treadmill belt was set in motion at the

4 adequate running speed before the beginning of the exercise period. The children were instructed to

5 put their feet on both sides of the belt of the treadmill and to get on the belt at the beginning of the exercise period. For intermittent exercises, as the treadmill was not stopped at the end of each 15second period of running or passive recovery. Leaving the treadmill consisted in putting their feet on intermittent exercises and were helped by an adult.

Continuous exercises intensities corresponded to 60\% (CE60), 70\% (CE70) and 80\% (CE80) of MAS. These intensities were always performed in this order. The intermittent exercise intensities corresponded to $90 \%$ (IE90), 100\% (IE100) and 110\% (IE110) of MAS and here also, this order was kept for all the subjects. These MAS intensity percentages were chosen as they are frequently used measurement corresponded to the time of exercise flow/volume loop measurement.

\section{Determination of ventilatory constraints}

For each continuous and intermittent exercise, ventilatory constraints were firstly determined with the calculation of breathing reserve (BR). BR was calculated based on maximal $\dot{V} E$ reached during the exercise and the estimated maximal voluntary ventilation (MVV). It corresponded to how closely 
1 maximal $\dot{V} E$ achieved during exercise approached MVV. The BR calculation equation was the

2 following:

3

4

5

6 where MVV was determined according to the following equation ${ }^{6,23}: \mathrm{MVV}=\mathrm{FEV}_{1} \times 35$ and $\dot{\mathrm{VE}}_{\max }$

7 corresponded to the maximal value of $\dot{V} E$ reached during each continuous or intermittent exercise.

8 The MVV was estimated for each exercise performed, with the $\mathrm{FEV}_{1}$ measured just before the 9 10 11

$$
\mathrm{BR}(\%)=\left[\left(\mathrm{MVV}-\dot{\mathrm{V}} \mathrm{E}_{\max }\right) / \mathrm{MVV}\right] \times 100
$$

exercise.

In order to evaluate mechanical ventilatory constraints and breathing strategy during the exercise, exercise tidal flow/volume loops (tidal F/V loops) were recorded just once, at the end of the first 30 seconds of the last minute of each exercise using a pneumotachograph. Tidal F/V loops corresponded to a mean of ten tidal breaths recorded and were computer averaged before a maximal inspiratory capacity (IC) maneuver. This maneuver allows correction of drift phenomena, as described by Johnson et al ${ }^{6}$. During exercise, a drift phenomenon could appear in the volume signal due to electrical or physiological changes over time. This drift must be corrected in order to obtain correctly placed tidal F/V loops within MFVL. Thus, the maximal inspiratory capacity maneuver was performed immediately after tidal F/V loop measurement. This maximal IC maneuver was compared to the maximal IC determined at rest. After the maneuver, the computer could correctly plot tidal F/V loops within the MFVL determined before the exercise. For each tidal F/V loop measurement, the mean values of $\dot{\mathrm{V}} \mathrm{O}_{2}, \dot{\mathrm{VE}}, \mathrm{Vt}, f, \dot{\mathrm{VE}} / \dot{\mathrm{V}}_{2}, \dot{\mathrm{VE}} / \dot{\mathrm{VCO}}_{2}$ and $\mathrm{HR}$ were calculated at the moment of measurement (corresponding to the mean of the first 30 seconds of the last minute of exercise).

Expiratory flow limitation (expFL) corresponds to the part of tidal F/V loop that meets or exceeds the expiratory boundary of the MFVL and is expressed as a \% of tidal volume (\%Vt). In order to determine breathing strategy, the evolution of different ratios was analyzed. Hence, 


\section{1}

2

1 inspiratory capacity (IC) relative to forced vital capacity (IC/FVC $)^{6}$, expiratory reserve volume relative

2 to vital capacity (ERV/FVC), tidal volume relative to inspiratory capacity $(\mathrm{Vt} / \mathrm{IC})^{6}$ and inspiratory

3 reserve volume relative to vital capacity (IRV/FVC) were estimated computed (Figure 2).

4

\section{Statistical analysis}

6 All the values were expressed as means \pm standard deviation (mean \pm SD). For each parameter, data

7 normality was verified with a Kolmogorov-Smirnov test.

8 In order to determine the effect of exercise modality, a two-way repeated measure analysis of

9 variance (ANOVA) was performed for all the parameters. The factors were "exercise intensity" and 10 "exercise modality". When the ANOVA F ratio was significant, the mean values were compared by 11 using pairwise multiple comparison procedures (Bonferroni post-hoc test).

12 For intra-modality comparison, a one-way repeated measure analysis of variance (ANOVA) was 13 performed for all the parameters. The factor was "exercise intensity". When the ANOVA F ratio was 14 significant, the mean values were compared by using pairwise multiple comparison procedures 15 (Bonferroni post-hoc test).

16 For rest versus exercise values comparison within the same modality, a "paired t-test" was carried 17 out.

18 For all the tests, significance was set at the 0.05 level. 


\section{$1 \quad$ Results}

2

3 Anthropometric, spirometric and maximal values at incremental exercise

$4 \quad$ Respiratory data from one subject were unworkable. Thus, anthropometric, spirometric and maximal 5 exercise values of the eleven children were analyzed ( 8 boys and 3 girls; Table 1 ). For each child, 3 6 criteria of maximality at least were fulfilled, showing that the graded exercise was maximal.

7

8 Mean cardiorespiratory values $\left(\dot{\mathrm{VO}}_{2}, \mathrm{HR}, \mathrm{RER}\right)$ measured during continuous and intermittent 9 10

exercises for the whole population are shown in Table 2. For $\dot{\mathrm{VO}}_{2}$ only, a significant "intensity $\mathrm{x}$ modality" interaction and an "intensity" effect were highlighted. However, post-hoc tests revealed no significant difference between continuous and intermittent exercises within the three different intensity levels (ie. CE60 vs. IE90, CE70 vs. IE100 and CE80 vs. IE110), allowing the comparison of the ventilatory data obtained during each exercise modality. For HR, an significant intensity effect was highlighted for both modalities, without "modality" effect. Finally, no effect of the exercise modality and intensity was found for Respiratory Exchange Ratio (RER).

\section{Ventilatory response to exercise}

\section{Breathing pattern}

The mean values of ventilation are shown in Table 3. Two-way ANOVA analysis highlights "intensity" and "modality $x$ intensity" interaction effects for ventilation $(p<0.05)$. An "intensity" effect $(p<0.001)$ was found for $\dot{V} E$ in continuous exercise $(p<0.001)$ but not in intermittent exercise $(p=0.08)$. Following post-hoc tests, for each level of exercise intensity (CE60 vs. IE90, CE70 vs. I100 and CE80 vs. IE110), ventilation and dyspnea scores were not significantly different between continuous and intermittent exercises. For tidal volume (Vt), no "intensity" or "modality" effects were found for 
1 either CE or IE modalities. Concerning respiratory frequency $(f)$, an "intensity" effect was found for IE

$2 \quad(p<0.05)$ and a tendency towards significant effect for CE $(p=0.06)$. No "modality" effect was found

3 for this parameter.

4

5

6

7

Mechanical ventilatory constraints

- Expiratory flow limitation

Expiratory flow limitation (expFL) was experienced by 1 child during CE60, 6 children during CE70 and 6 children during CE80. Concerning intermittent exercise, expFL was observed for 3,4 and 6 children during IE90, IE100 and IE110 respectively (Figure 3.b). Individual values of ExpFL ranged between 10 - $90 \%$ of Vt. Only one child showed expFL during all the continuous and intermittent exercises. Mean values of expFL for the whole population ranged from $5 \%$ to $29 \%$ of $\mathrm{Vt}$ and from $13 \%$ to $23 \%$ of $\mathrm{Vt}$ for the continuous and intermittent exercises respectively (Figure 3.a).

- Flow-limited (FL) vs. non flow-limited (NFL) comparison

Within each exercise, the population was divided into two groups according to the presence or absence of an expiratory flow limitation (expFL) during exercise. The children who presented expFL made up the flow-limited group (FL group). The non flow-limited group (NFL) was composed of the other children.

For continuous exercise at $60 \%$ of MAS, only one child experienced an expFL versus 10 children making up the NFL group, which made comparison impossible.

No significant difference was highlighted between the two groups for breathing pattern ( $\mathrm{Vt}$ and $f$ ) in any of the exercises.

Breathing reserve was significantly lower in the FL than the NFL group during continuous exercise, for CE70 (30.8 \pm 11.6 for FL and $48.8 \pm 10.2$ for NFL; $p=0.02)$ and CE80 $(21.8 \pm 10.1$ for FL and $42.1 \pm 10.9$ for NFL; $p=0.01$ ). During all intermittent exercises, no significant difference for $B R$ was found 
1 between FL and NFL groups for IE90 (38.8 \pm 1.2 for FL and $50.9 \pm 10.2$ for NFL), IE100 (33.9 \pm 7.9 for

2 FL and $45.2 \pm 12.2$ for NFL) and IE110 ( $24.2 \pm 22.2$ for FL and $46.7 \pm 13.9$ for NFL).

3

$4 \quad$ - Flow volume loops and tidal volume regulation.

5 The mean values of resting and exercise pulmonary parameters are recapitulated in Table 4. IRV

6 decreased significantly from rest to exercise for all continuous or intermittent exercises $(p<0.05)$. ERV

7 increased significantly from rest to exercise for CE70, IE100 and IE110 ( $p<0.05)$. For IC, a significant

8 difference was observed between rest and exercise for CE70, IE100 and IE110 ( $p<0.05)$. No significant

9 differences were found for IC/FVC and ERV/FVC between rest and exercise values, except for IE110

$10(p<0.05)$. IRV/FVC decreased significantly between rest and exercise for all the exercises. In the same

11 way, Vt/IC was significantly higher than at rest for all the exercises except for CE70 and IE100 $12(\mathrm{p}<0.05)$.

13

14 For all the parameters of mechanical ventilatory constraints (expFL, Vt/IC, IC/FVC, IRV/FVC and 15 ERV/FVC), there were no significant "modality" and "intensity" effects (Table 4 and Figure 3.a).

16 However, an "intensity" effect tended to be significant for expFL during continuous exercise $17(p=0.065)$. 


\section{Discussion}

2 The purpose of the study was to evaluate the ventilatory response during continuous and

3 intermittent exercises and to determine if one of these two exercise modalities could induce greater

4 mechanical ventilatory constraints than the other. Our results showed that both exercise modalities

5 (continuous and intermittent) could induce mechanical ventilatory constraints in healthy

6 prepubescent children, as several children presented expiratory flow limitation (expFL) during

7 continuous and intermittent exercises with no influence due to exercise modality.

8

9 Some limits should be considered for this study, mainly concerning recorded exercise flow/volume 10 loops. As mentioned by some authors ${ }^{6,13}$, expFL assessment is highly dependent on the placement of exercise flow/volume loop within maximal flow/volume loop. This limit has been taken in account with the realization of inspiratory capacity (IC) maneuvers after exercise flow/volume loop measurement, allowing drift correction. The IC maneuver has already been used to enhance reproducibility of the flow/volume loop method ${ }^{6}$.

As described above, the aim of the study was to compare mechanical ventilatory constraints (expiratory flow limitation and dynamic hyperinflation) and breathing pattern (ventilation, tidal volume and breathing frequency) during continuous and intermittent exercises with exercise intensities inducing similar metabolic demand. Even if a significant interaction for oxygen uptake was highlighted, it appears that, within the different levels of exercise intensity (low, medium and high), the metabolic demand $\left(\dot{\mathrm{VO}}_{2}\right)$ was matching between the pair of tasks concerning the two exercise modalities. In other words, no significant difference was highlighted for $\dot{\mathrm{VO}}_{2}$ between CE60 vs. IE90, CE70 vs. IE100 and CE80 vs. IE110, allowing the comparison of the breathing pattern data and the mechanical ventilatory constraints data obtained during each exercise. 
2 As expected, ventilation for the continuous exercise modality increased with greater exercise

3 intensity. However, during intermittent exercises, ventilation increased slightly, but not significantly,

4 with the increase in exercise intensity. These specific ventilation evolutions according to exercise

5 modality could be due to the fact that, during $15 \mathrm{~s}-15 \mathrm{~s}$ intermittent exercises performed by the

6

7 children in this study, the time of running was rather short. Hence, the ventilatory system would not seem to have enough time to adapt to the ventilatory demand induced by the exercise intensity. However, within the three intensity levels (i.e. low, medium or high), no significant difference was highlighted between continuous and intermittent exercises. These results could logically be explained since the intensities of intermittent exercises were specifically chosen in order to be matched with continuous exercise intensities in terms of energy expenditure (i.e. oxygen uptake), as already reported by Berthoin et al. ${ }^{24}$ The absence of significant difference for ventilation between both exercise modalities was also required in order to compare breathing pattern components (Vt and f) correctly. In fact, several studies have reported that for a particular subject, the regulation of the breathing pattern at a given level of ventilation is largely independent of the cause of the increased ventilation ${ }^{25,26}$.

During all the continuous and the intermittent exercises, our results showed that the increase in ventilation was mainly due to an increase in respiratory frequency. This result supports the findings in the literature ${ }^{5}$ and revealed that, whatever the exercise modality, children presented rapid and shallow breathing. However, differences in ventilatory regulation according to exercise modality seemed to exist, as a "modality" effect was found for ventilatory equivalent in carbon dioxide $\left(\dot{\mathrm{VE}} / \dot{\mathrm{V}} \mathrm{CO}_{2}\right)$. Post-hoc analysis revealed that, in general, intermittent exercise modality induced higher $\dot{\mathrm{VE}} / \dot{\mathrm{V}} \mathrm{CO}_{2}$ values than continuous exercise modality. This could be explained firstly, by a chemical regulation due to a higher acidosis level during intermittent exercise and, secondly, by a 
movement frequency encountered during intermittent exercise which could induce a greater

2 ventilatory response ${ }^{27}$.

3

\section{Effects of exercise intensity on mechanical ventilatory constraints}

5 As described by Johnson et al $^{6}$, the assessment of breathing reserve (BR) could be an indicator of the occurrence of mechanical ventilatory constraints during exercise. In all the previous studies reporting

7 BR values in children, the exercise performed has been incremental ${ }^{13,14,28-30}$. This difference in protocols makes it impossible to compare our results with the previous studies, which is normal, since this is the originality of our study. In our study, BR significantly decreased during CE and IE whereas there was no "intensity" effect for $\dot{V} E$ during IE. This result is surprising and reinforces the 11 work of Johnson et al. ${ }^{6}$ asserting that breathing reserve is a general and inappropriate parameter for the study of mechanical ventilatory constraints during exercise.

The study of mechanical ventilatory constraints with exercise flow/volume loops brings more information on the adaptation of the ventilatory system during exercise.

In our study, the number of expiratory flow limitation cases increased with exercise intensity in both exercise modalities. For the highest intensity exercises, more than $50 \%$ of the whole population ( 6 of the 11 children studied) showed an expiratory flow limitation. Individual expiratory flow limitation ranged between $10-90 \%$ of $\mathrm{Vt}$. These values are in accordance with values of expFL found in the literature. In fact, Nourry et al. ${ }^{13}$ reported an increase in the number of observations of expFL in nonathlete prepubescent children ( 8 children out of the 18 studied) with the increase in intensity during 21 the maximal graded test, ranging between $16-78 \%$ of $\mathrm{Vt}$. The occurrence of expFL during sub22 maximal (CE60, CE70, CE80 and IE90) and supra-maximal (IE100, IE110) exercises is not surprising, 23 since a previous study has reported the case of expFL from $30 \%$ of maximal aerobic power ${ }^{13}$ and 24 intensities prescribed in our study were all higher than this threshold value. As with ventilatory response during exercise, the occurrence of expFL in our population was heterogeneous as some 
1 children experienced expFL during IE90 and IE110 but not during IE100 for example. The

2 heterogeneity of expFL occurrence has also previously been described in children ${ }^{13}$ and could be 3 explained by the different levels of ventilatory system maturation.

4 Thus, for both exercise modalities, the increase in ventilation was generally associated with a 5 significant decrease in IRV and IRV/FVC and an increase in Vt/IC from rest to exercise without 6 significant modification of ERV/FVC and IC/FVC ratios, whatever the exercise performed. These 7 results attested to the absence of dynamic hyperinflation. The absence of significant modification of ERV/FVC and IC/FVC ratios during exercise attested to a specific breathing pattern for children, whatever the exercise modality, in comparison with an adult population.

10

\section{Effects of exercise modality on mechanical ventilatory constraints}

The exercise modality had no effect on breathing reserve, as similar values were found during continuous and intermittent exercises for the three intensity levels. Tidal volume regulation was not influenced by a "modality" effect either. Following statistical analysis, exercise modality was noted to have no effect on the occurrence and/or the severity of expFL. This absence of "modality" effect invalidated our hypothesis. In fact, as higher intensities are frequently used during intermittent exercises, we had hypothesized that the higher ventilatory demand induced by the high-intensity intermittent exercises would induce greater mechanical ventilatory constraints. The absence of a "modality" effect for ventilation could be an explanation for the absence of a "modality" effect on mechanical ventilatory constraints.

In the present study, the assessment of the ventilatory response corresponded to an intermittent exercise design comprising $15 \mathrm{~s}$ of exercise followed by $15 \mathrm{~s}$ of passive recovery. However many modalities of intermittent exercises exist, such as $30 \mathrm{~s}-30 \mathrm{~s}$, with passive or active recovery ${ }^{24}$. Our results may only be relevant for this intermittent exercise design. In fact, any change in parameters 
1 defining intermittent exercises could modify the ventilatory response values and so alter the

2 breathing pattern, breathing strategy and the occurrence of mechanical ventilatory constraints

3 during intermittent exercises. Yet, on the other hand, the $15 \mathrm{~s}-15 \mathrm{~s}$ design was chosen as this

$4 \quad$ intermittent exercise design has previously been used quite often in the literature and has generally

5 been well accepted by children ${ }^{24,31}$.

6

7 In conclusion, exercise modality does not seem to be a predominant factor in mechanical ventilatory

8 constraint occurrence during exercise. Nevertheless, the exercise intensity seems to be an important

9 factor in inducing mechanical ventilatory constraints, as the number of occurrences and the severity increased with intensity increased. We could conclude that neither of the modalities studied induced

11 more or greater mechanical ventilatory constraints than the other, but exercise intensities specific to

12 each modality might be greater sources of exacerbation for mechanical ventilatory constraints.

13

\section{Acknowledgements}

15

We thank all the children and their parents who took part in this study for their participation and their devotion. Data quality assurance was assumed by Clinical Investigation Center of Lille (CIC-9301Inserm-CHRU). Regulatory aspects were performed by the designed "Good Clinical Practices sponsor" as University Regional Centre Hospital (CHRU). Financial support was assumed by a grant from the French Ministry of Health (regional PHRC $n^{\circ} 1904-2005$ ). 


\section{$\underline{\text { References }}$}

1. Nagano $Y$, Baba R, Kuraishi K, Yasuda T, Ikoma M, Nishibata K, Yokota M, Nagashima M. Ventilatory control during exercise in normal children. Pediatr Res 1998;43(5):704-707.

2. Rowland TW, Cunningham LN. Development of ventilatory responses to exercise in normal white children. A longitudinal study. Chest 1997;111(2):327-332.

3. Cooper DM, Kaplan MR, Baumgarten L, Weiler-Ravell D, Whipp BJ, Wasserman K. Coupling of ventilation and CO2 production during exercise in children. Pediatr Res 1987;21(6):568-572.

4. Andersen KL, Seliger V, Rutenfranz J, Messel S. Physical performance capacity of children in Norway. III. Respiratory responses to graded exercise loadings--population parameters in a rural community. Eur J Appl Physiol Occup Physiol 1974;33(4):265-274.

5. Gratas-Delamarche A, Mercier J, Ramonatxo M, Dassonville J, Prefaut C. Ventilatory response of prepubertal boys and adults to carbon dioxide at rest and during exercise. Eur J Appl Physiol Occup Physiol 1993;66(1):25-30.

6. Johnson BD, Weisman IM, Zeballos RJ, Beck KC. Emerging concepts in the evaluation of ventilatory limitation during exercise: the exercise tidal flow-volume loop. Chest 1999;116(2):488-503.

7. Babb TG. Mechanical ventilatory constraints in aging, lung disease, and obesity: perspectives and brief review. Med Sci Sports Exerc 1999;31(1 Suppl):S12-22.

8. DeLorey DS, Babb TG. Progressive mechanical ventilatory constraints with aging. Am J Respir Crit Care Med 1999;160(1):169-177.

9. Babb TG, Viggiano R, Hurley B, Staats B, Rodarte JR. Effect of mild-to-moderate airflow limitation on exercise capacity. J Appl Physiol 1991;70(1):223-230.

10. Johnson BD, Saupe KW, Dempsey JA. Mechanical constraints on exercise hyperpnea in endurance athletes. J Appl Physiol 1992;73(3):874-886.

11. Johnson BD, Reddan WG, Seow KC, Dempsey JA. Mechanical constraints on exercise hyperpnea in a fit aging population. Am Rev Respir Dis 1991b;143(5 Pt 1):968-977.

12. Johnson BD, Reddan WG, Pegelow DF, Seow KC, Dempsey JA. Flow limitation and regulation of functional residual capacity during exercise in a physically active aging population. Am Rev Respir Dis 1991a;143(5 Pt 1):960-967.

13. Nourry C, Deruelle F, Fabre C, Baquet G, Bart F, Grosbois JM, Berthoin S, Mucci P. Evidence of ventilatory constraints in healthy exercising prepubescent children. Pediatr Pulmonol 2006;41(2):133-140.

14. Nourry C, Deruelle F, Fabre C, Baquet G, Bart F, Grosbois JM, Berthoin S, Mucci P. Exercise flow-volume loops in prepubescent aerobically trained children. J Appl Physiol 2005;99(5):1912-1921.

15. Tanner. Growth at Adolescence (2nd Ed.). Oxford, UK; 1962.

16. Society AT. Standardization of spirometry--1987 update. Official statement of American Thoracic Society. Respir Care 1987;32(11):1039-1060.

17. Borg GA. Psychophysical bases of perceived exertion. Med Sci Sports Exerc 1982;14(5):377381.

18. Fawkner SG, Armstrong N, Potter CR, Welsman JR. Oxygen uptake kinetics in children and adults after the onset of moderate-intensity exercise. J Sports Sci 2002;20(4):319-326.

19. Tanaka H, Monahan KD, Seals DR. Age-predicted maximal heart rate revisited. J Am Coll Cardiol 2001;37(1):153-156.

20. Tolfrey K, Campbell IG, Batterham AM. Exercise training induced alterations in prepubertal children's lipid-lipoprotein profile. Med Sci Sports Exerc 1998;30(12):1684-1692.

21. Billat LV, Koralsztein JP. Significance of the velocity at VO2max and time to exhaustion at this velocity. Sports Med 1996;22(2):90-108. 
22. Baquet $\mathrm{G}$, van Praagh $\mathrm{E}$, Berthoin $\mathrm{S}$. Endurance training and aerobic fitness in young people. Sports Med 2003;33(15):1127-1143.

23. Stein R, Selvadurai H, Coates A, Wilkes DL, Schneiderman-Walker J, Corey M. Determination of maximal voluntary ventilation in children with cystic fibrosis. Pediatr Pulmonol 2003;35(6):467-471.

24. Berthoin S, Baquet G, Dupont G, Van Praagh E. Critical velocity during continuous and intermittent exercises in children. Eur J Appl Physiol 2006;98(2):132-138.

25. Hey EN, Lloyd BB, Cunningham DJ, Jukes MG, Bolton DP. Effects of various respiratory stimuli on the depth and frequency of breathing in man. Respir Physiol 1966;1(2):193-205.

26. Gallagher $\mathrm{CG}$, Brown $\mathrm{E}$, Younes $\mathrm{M}$. Breathing pattern during maximal exercise and during submaximal exercise with hypercapnia. J Appl Physiol 1987;63(1):238-244.

27. Takano N. Effects of pedal rate on respiratory responses to incremental bicycle work. J Physiol 1988;396:389-397.

28. Armstrong N, Kirby BJ, McManus AM, Welsman JR. Prepubescents' ventilatory responses to exercise with reference to sex and body size. Chest 1997;112(6):1554-1560.

29. Prioux J, Matecki S, Amsallem F, Denjean A, Ramonatxo M. [Ventilatory response to maximal exercise in healthy children]. Rev Mal Respir 2003;20(6 Pt 1):904-911.

30. Prioux J, Matecki S, Mercier J, Prefaut C, Ramonatxo M. Ventilatory reserve at maximal exercise in children. A transversal study. Pflügers Arch 2000;440:215.

31. Dupont G, Blondel N, Lensel G, Berthoin S. Critical velocity and time spent at a high level of VO2 for short intermittent runs at supramaximal velocities. Can J Appl Physiol 2002;27(2):103-115. 


\section{Figure legends}

Figure 1: Design of continuous and intermittent exercise tests.

With MAS: maximal aerobic speed. For intermittent modality, each vertical band corresponds to a $15 \mathrm{sec}$ exercise period.

Figure 2: Exercise tidal volume plotted within maximal flow/volume loop

With MFVL: maximal flow/volume loop determined at rest; ExpFL : expiratory flow limitation corresponding to the part of tidal flow/volume loop that meets or exceeds MFVL; EELV : end-expiratory lung volume determined by inspiratory capacity relative to forced vital capacity; EILV : end-inspiratory lung volume determined by tidal volume relative to inspiratory capacity; Vt : tidal volume; IRV: inspiratory reserve volume; ERV : expiratory reserve volume; FVC : forced vital capacity; IC : inspiratory capacity.

Figure 3: Expiratory flow limitation during the six performed exercises.

Values are expressed as mean \pm SD. Graph 3.a : mean expiratory flow limitation for the whole population. Graph 3.b : mean expiratory flow limitation for the flow-limited group. ExpFL corresponds to expiratory flow limitation expressed in percentage of tidal volume that meets or exceeds maximal flow/volume loop. Thus, the flow limit group was composed of the children who showed an expFL during exercise.

CE60, CE70 and CE80 correspond to continuous exercise at $60 \%, 70 \%$ and $80 \%$ of maximal aerobic speed; IE90, IE100 and IE110 to intermittent exercise at $90 \%, 100 \%$ and $110 \%$ of maximal aerobic speed. 
Table 1: Anthropometric, spirometric and maximal values at incremental exercise.

\begin{tabular}{|c|c|}
\hline Parameter (units) & Mean \pm SD \\
\hline Age (years) & $8.6 \pm 1.4$ \\
\hline Height $(\mathrm{cm})$ & $135.2 \pm 9.4$ \\
\hline Body mass (kg) & $29.0 \pm 5.8$ \\
\hline BMI $\left(\mathrm{kg} \cdot \mathrm{cm}^{-2}\right)$ & $15.7 \pm 1.5$ \\
\hline FVC (L) & $2.1 \pm 0.4$ \\
\hline FVC (\% of theoritical value) & $99.6 \pm 11.5$ \\
\hline $\mathrm{FEV}_{1}(\mathrm{~L})$ & $1.8 \pm 0.4$ \\
\hline FEV1 (\% of theoritical value) & $101.8 \pm 12.3$ \\
\hline $\mathrm{VO}_{2 \max }\left(\right.$ L. $\left.\min ^{-1}\right)$ & $1.5 \pm 0.4$ \\
\hline $\mathrm{VO}_{2 \max }\left(\mathrm{mL} \cdot \mathrm{min}^{-1} \cdot \mathrm{kg}^{-1}\right)$ & $50.3 \pm 8.2$ \\
\hline HR max (bpm) & $186.5 \pm 10.6$ \\
\hline RER max & $1.0 \pm 0.1$ \\
\hline MAS $\left(\mathrm{km} \cdot \mathrm{h}^{-1}\right)$ & $10.0 \pm 1.6$ \\
\hline
\end{tabular}

With BMI : Body Mass Index ; FVC : Forced Vital Capacity ; FEV 1 : Forced Expiratory Volume in 1 Second ; $\mathrm{VO}_{2 \text { peak }}$ : peak oxygen uptake; HRmax : maximal heart rate; RERmax : maximal respiratory exchange ratio; MAS : maximal aerobic speed. 
Table 2 : Cardio-respiratory data during continuous and intermittent exercises

\begin{tabular}{|c|c|c|c|c|c|c|}
\hline \multirow{2}{*}{$\begin{array}{c}\text { Intensity level } \\
\text { Exercise }\end{array}$} & \multicolumn{2}{|c|}{ Low } & \multicolumn{2}{|c|}{ Medium } & \multicolumn{2}{|c|}{ High } \\
\hline & CE60 & IE90 & CE70 & IE100 & CE80 & IE110 \\
\hline $\mathrm{VO}_{2}\left(\operatorname{L} \cdot \mathrm{min}^{-1}\right)$ & $0.92 \pm 0.27 \$ \mu$ & $1.03 \pm 0.22 \mu$ & $1.10 \pm 0.27 \S$ & $1.19 \pm 0.31$ & $1.27 \pm 0.33$ & $1.17 \pm 0.35$ \\
\hline $\mathrm{HR}(\mathrm{bpm})$ & $135.0 \pm 11.9 \$ \mu$ & $146.4 \pm 17.3 \mu$ & $152.1 \pm 10.6 \S$ & $151.2 \pm 8.1$ & $163.6 \pm 16.8$ & $158.2 \pm 11.3$ \\
\hline RER & $0.94 \pm 0.05$ & $0.94 \pm 0.07$ & $0.96 \pm 0.04$ & $0.92 \pm 0.06$ & $0.98 \pm 0.04$ & $0.96 \pm 0.06$ \\
\hline
\end{tabular}

Values are expressed in mean \pm SD. CE60, CE70 and CE80 represented continuous exercises at $60 \%, 70 \%$ and $80 \%$ of maximal aerobic speed (MAS). IE90, IE100 and IE110 represented intermittent exercises at $90 \%, 100 \%$ and $110 \%$ of $\mathrm{MAS} \mathrm{VO}_{2}$ : oxygen uptake; HR : heart rate; RER : Respiratory exchange ratio.

$\$: p<0.05$ for CE60 vs. CE70

$\S: p<0.05$ for CE70 vs. CE80

$\mu: p<0.05$ for CE60 vs. CE80 or IE90 vs. IE110 comparisons 
Table 3: Respiratory parameters for the continuous and intermittent exercises.

\begin{tabular}{|c|c|c|c|c|c|c|}
\hline \multirow{2}{*}{$\frac{\text { Intensity level }}{\text { Exercise }}$} & \multicolumn{2}{|c|}{ Low } & \multicolumn{2}{|c|}{ Middle } & \multicolumn{2}{|c|}{ High } \\
\hline & CE60 & IE90 & CE70 & IE100 & CE80 & IE110 \\
\hline $\mathrm{V}_{\mathrm{E}}\left(L \cdot \min ^{-1}\right)$ & $28.6 \pm 7.5 \$ \mu$ & $33.1 \pm 6.5$ & $33.7 \pm 7.8 \S$ & $36.6 \pm 8.7$ & $38.7 \pm 8.4$ & $36.8 \pm 9.7$ \\
\hline $\mathrm{Vt}(m L)$ & $616.8 \pm 230.4$ & $665.6 \pm 224.8$ & $665.5 \pm 317.5$ & $603.1 \pm 145.5$ & $687.1 \pm 350.0$ & $585.1 \pm 194.8$ \\
\hline$f\left(\right.$ cycles. $\left.\min ^{-1}\right)$ & $49.8 \pm 16.5$ & $51.8 \pm 12.2 \mu$ & $57.4 \pm 19.5$ & $63.0 \pm 18.4$ & $64.4 \pm 22.7$ & $67.4 \pm 23.6$ \\
\hline $\mathrm{V}_{\mathrm{E}} / \mathrm{VO}_{2}$ & $31.8 \pm 3.3$ & $32.3 \pm 3.0$ & $31.2 \pm 2.9$ & $31.0 \pm 3.4$ & $31.6 \pm 3.3$ & $33.2 \pm 4.8$ \\
\hline $\mathrm{V}_{\mathrm{E}} / \mathrm{VCO}_{2}$ & $32.4 \pm 2.6$ & $32.9 \pm 2.9$ & $32.1 \pm 3.1$ & $33.2 \pm 3.0$ & $31.6 \pm 2.7$ & $33.0 \pm 2.9$ \\
\hline BR (\%) & $51.4 \pm 12.4 \mathbf{\$} \boldsymbol{\mu}$ & $46.9 \pm 9.7 \mu$ & $39.0 \pm 14.0 \S$ & $41.1 \pm 11.8$ & $31.1 \pm 14.5$ & $34.5 \pm 21.5$ \\
\hline Dyspnea & $1.1 \pm 1.2 \$$ & $1.1 \pm 1.5 \mu$ & $3.1 \pm 2.4$ & $2.2 \pm 2.2$ & $3.6 \pm 2.7$ & $3.5 \pm 2.2$ \\
\hline
\end{tabular}

Values are expressed in mean \pm SD. CE60, CE70 and CE80 represented continuous exercises at $60 \%, 70 \%$ and $80 \%$ of maximal aerobic speed (MAS). IE90, IE100 and IE110 represented intermittent exercises at $90 \%, 100 \%$ and $110 \%$ of $\mathrm{MAS} \mathrm{VO}_{2}$ : oxygen uptake; mean $\mathrm{VO}_{2}$ : mean oxygen uptake of the last two minutes of exercise; $\mathrm{VE}$ : ventilation at tidal $\mathrm{FV}$ loop measurement; $\mathrm{Vt}$ : tidal volume; $f$ : respiratory frequency; $\mathrm{VE} / \mathrm{VO}_{2}$ and $\mathrm{VE} / \mathrm{VCO}_{2}$ : respiratory equivalent in oxygen and in carbon dioxide; BR: breathing reserve.

$\$: p<0.05$ for CE60 vs. CE70 or IE90 vs. IE100 comparisons

$\S: p<0.05$ for CE70 vs. CE80 or IE100 vs. IE110 comparisons

$\mu: p<0.05$ for CE60 vs. CE80 or IE90 vs. IE110 comparisons 
Table 4: Ventilatory response at rest and during exercise.

\begin{tabular}{|c|c|c|c|c|c|c|}
\hline \multicolumn{7}{|c|}{ Continuous exercise } \\
\hline & \multicolumn{2}{|c|}{ CE60 } & \multicolumn{2}{|c|}{ CE70 } & \multicolumn{2}{|c|}{ CE80 } \\
\hline & Rest & Exercise & Rest & Exercise & Rest & Exercise \\
\hline Vt & $0.49 \pm 0.23$ & $0.62 \pm 0.23$ & $0.55 \pm 0.29$ & $0.67 \pm 0.32$ & $0.51 \pm 0.25$ & $0.69 \pm 0.35 *$ \\
\hline IRV & $1.00 \pm 0.25$ & $0.79 \pm 0.19 * *$ & $0.91 \pm 0.28$ & $0.68 \pm 0.25 *$ & $0.95 \pm 0.18$ & $0.67 \pm 0.17 * *$ \\
\hline ERV & $0.65 \pm 0.24$ & $0.74 \pm 0.26$ & $0.63 \pm 0.22$ & $0.74 \pm 0.23 *$ & $0.64 \pm 0.25$ & $0.74 \pm 0.29$ \\
\hline IC & $1.49 \pm 0.26$ & $1.40 \pm 0.24$ & $1.47 \pm 0.31$ & $1.35 \pm 0.27 *$ & $1.45 \pm 0.30$ & $1.35 \pm 0.35$ \\
\hline $\mathrm{Vt} / \mathrm{IC}$ & $0.32 \pm 0.14$ & $0.43 \pm 0.11 *$ & $0.37 \pm 0.19$ & $0.48 \pm 0.16$ & $0.34 \pm 0.12$ & $0.49 \pm 0.13 * *$ \\
\hline IC/FVC & $0.70 \pm 0.08$ & $0.66 \pm 0.07$ & $0.70 \pm 0.07$ & $0.65 \pm 0.07$ & $0.70 \pm 0.08$ & $0.65 \pm 0.11$ \\
\hline IRV/FVC & $0.47 \pm 0.09$ & $0.38 \pm 0.09 * *$ & $0.44 \pm 0.13$ & $0.34 \pm 0.13^{*}$ & $0.47 \pm 0.09$ & $0.33 \pm 0.12 * *$ \\
\hline ERV/FVC & $0.30 \pm 0.08$ & $0.34 \pm 0.07$ & $0.30 \pm 0.07$ & $0.35 \pm 0.07$ & $0.30 \pm 0.08$ & $0.35 \pm 0.11$ \\
\hline \multicolumn{7}{|c|}{ Intermittent exercise } \\
\hline & \multicolumn{2}{|c|}{ IE90 } & \multicolumn{2}{|c|}{ IE100 } & \multicolumn{2}{|c|}{ IE110 } \\
\hline & Rest & Exercise & Rest & Exercise & Rest & Exercise \\
\hline $\mathrm{Vt}$ & $0.55 \pm 0.24$ & $0.67 \pm 0.23$ & $0.58 \pm 0.30$ & $0.60 \pm 0.15$ & $0.48 \pm 0.16$ & $0.59 \pm 0.20$ \\
\hline IRV & $0.96 \pm 0.24$ & $0.76 \pm 0.20 *$ & $0.88 \pm 0.24$ & $0.72 \pm 0.23 *$ & $0.97 \pm 0.18$ & $0.72 \pm 0.11 * *$ \\
\hline ERV & $0.61 \pm 0.24$ & $0.71 \pm 0.32$ & $0.66 \pm 0.18$ & $0.80 \pm 0.18 *$ & $0.60 \pm 0.22$ & $0.74 \pm 0.23 *$ \\
\hline IC & $1.51 \pm 0.36$ & $1.42 \pm 0.31$ & $1.45 \pm 0.33$ & $1.32 \pm 0.31 *$ & $1.45 \pm 0.20$ & $1.31 \pm 0.25 *$ \\
\hline $\mathrm{Vt} / \mathrm{IC}$ & $0.36 \pm 0.10$ & $0.47 \pm 0.10 *$ & $0.38 \pm 0.17$ & $0.46 \pm 0.08$ & $0.33 \pm 0.09$ & $0.44 \pm 0.08 *$ \\
\hline IC/FVC & $0.72 \pm 0.09$ & $0.68 \pm 0.11$ & $0.69 \pm 0.07$ & $0.62 \pm 0.07$ & $0.72 \pm 0.07$ & $0.64 \pm 0.08 *$ \\
\hline IRV/FVC & $0.46 \pm 0.10$ & $0.36 \pm 0.10 *$ & $0.42 \pm 0.09$ & $0.34 \pm 0.07 *$ & $0.48 \pm 0.10$ & $0.36 \pm 0.08 * *$ \\
\hline ERV/FVC & $0.28 \pm 0.09$ & $0.32 \pm 0.11$ & $0.31 \pm 0.07$ & $0.38 \pm 0.07$ & $0.28 \pm 0.07$ & $0.36 \pm 0.08 *$ \\
\hline
\end{tabular}

Values are expressed by mean \pm SD. CE60, CE70 and CE80 correspond to continuous exercise at $60 \%$, $70 \%$ and $80 \%$ of maximal aerobic speed; IE90, IE100 and IE110 to intermittent exercise at $90 \%, 100 \%$ and $110 \%$ of maximal aerobic.

Vt: tidal volume (liters), IRV: inspiratory reserve volume (liters), ERV: expiratory reserve volume (liters), IC: inspiratory capacity (liters), FVC: forced vital capacity (liters). ${ }^{*}: p<0.05, * *: p<0.01$. 
Figure 1
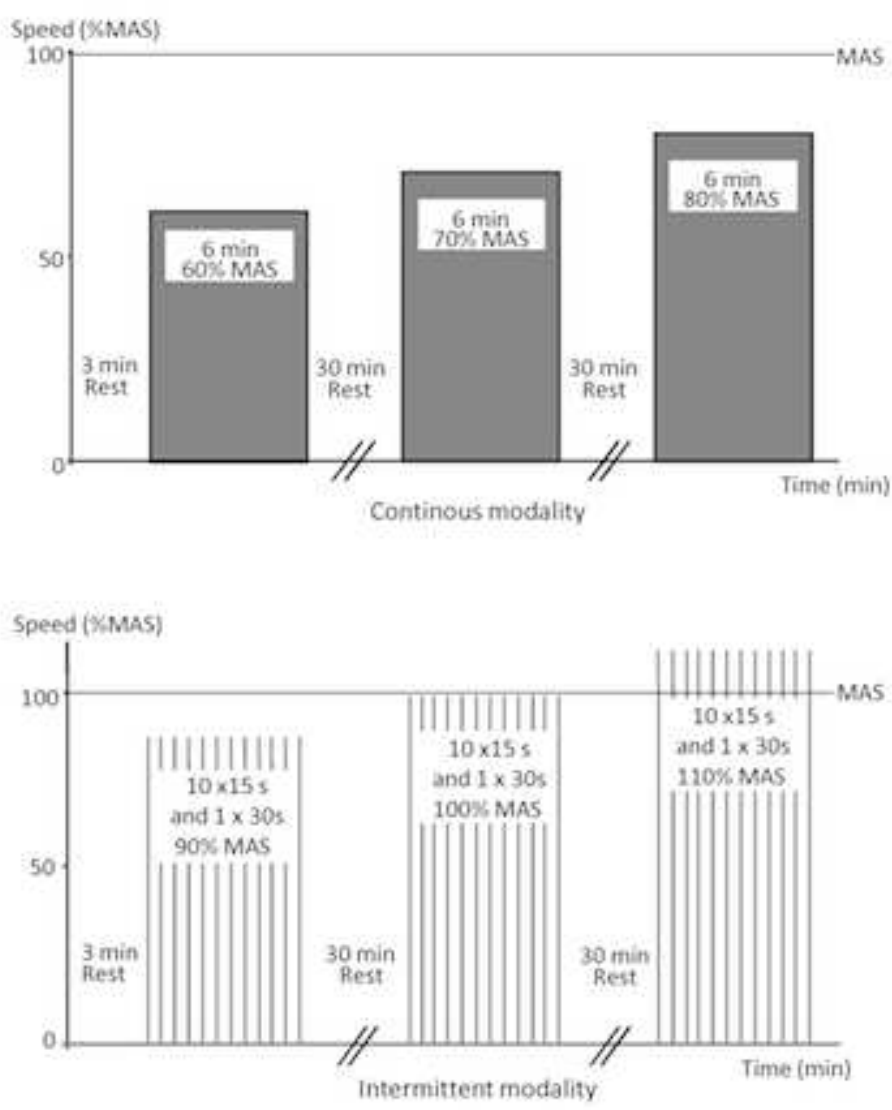

$32 \times 40 \mathrm{~mm}(300 \times 300$ DPI $)$

John Wiley \& Sons, Inc. 


1
2
3
4
5
6
7
8
9
10
11
12
13
14
15
16
17
18
19
20
21
22
23
24
25
26
27
28
29
30
31
32
33
34
35
36
37
38
39
40
41
42
43
44
45
46
47
48
49
50
51
52
53
54
55
56
57
58
60

Figure 2

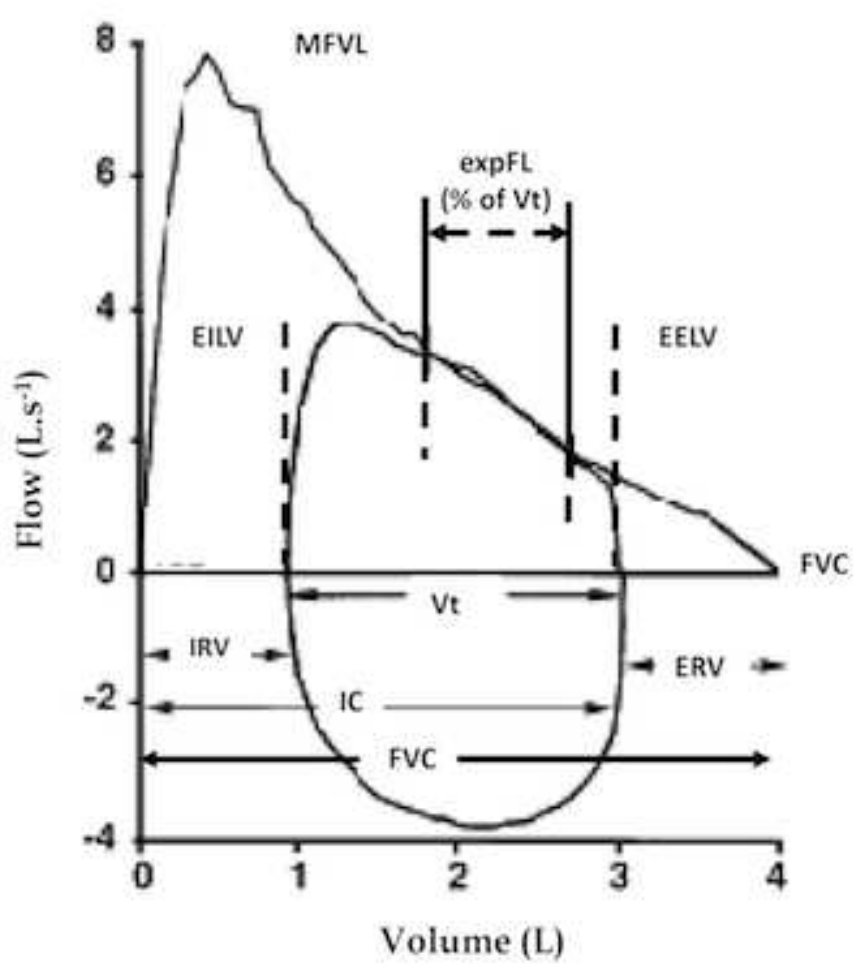

$28 \times 40 \mathrm{~mm}(300 \times 300 \mathrm{DPI})$

John Wiley \& Sons, Inc. 
3.a : Mean expiratory flow limitation for the whole population

Values are expressed as mean \pm SD. Graph 3.a : mean expiratory flow limitation for the whole population. Graph 3.b : mean expiratory flow limitation for the flow-limited group. ExpFL corresponds to expiratory flow limitation expressed in percentage of tidal volume that meets or exceeds maximal flow/volume loop. Thus, the flow limit group was composed of the children who showed an expFL during exercise.

CE60, CE70 and CE80 correspond to continuous exercise at $60 \%, 70 \%$ and $80 \%$ of maximal aerobic speed; IE90, IE100 and IE110 to intermittent exercise at $90 \%, 100 \%$ and $110 \%$ of maximal aerobic speed.

$352 \times 264 \mathrm{~mm}(72 \times 72 \mathrm{DPI})$

John Wiley \& Sons, Inc. 